CIUDAD Y TERRITORIO

ESTUDIOS TERRITORIALES

ISSN(P): 1133-4762; ISSN(E): 2659-3254

Vol. LII, № 206, invierno 2020

Págs. 777-790

https://doi.org/10.37230/CyTET.2020.206.04

CC BY-NC 4.0

\title{
Gandía: del barrio de Simancas a la Plaça de les Xocolateres. Un ejemplo de regeneración urbana en el marco de los Planes Estatales de Vivienda
}

Jorge Hervás-Más

Jefe de Servicio jurídico del Departamento de Urbanismo y Vivienda del Ayuntamiento de Gandía (Valencia). Profesor asociado del Departamento de Urbanismo de la Universidad Politécnica de Valencia.

RESUMEN: Gandía se ha ganado por derecho propio ser uno de los referentes más claros y relevantes en los procesos de regeneración y revitalización urbana gestionados últimamente en toda España. De hecho, la ciudad ducal, que ya disponía de una experiencia notable en la gestión de Áreas de Rehabilitación integral (500 viviendas del Grupo Porta) o en Fondos Europeos destinados a la reforma de barrios vulnerables (Programa Urban III en los barrios de Beniopa, Santa Ana y Plaça Elíptica), obtiene ahora como colofón un resultado excelente en el Área de Renovación urbana del barrio conocido como Grupo Simancas. El artículo realiza un análisis de las actuaciones llevadas a cabo por el Ayuntamiento de Gandía, conjuntamente con la Generalitat Valenciana y el Ministerio de Fomento, en el marco de las ayudas de los Planes Estatales de Vivienda para rehabilitar una de las zonas más vulnerables y desfavorecidas de la ciudad. Se trata de una renovación integral a través de la figura de las Áreas de Regeneración y Renovación Urbanas (ARRUS)de un complejo inmobiliario de 106 viviendas construido en los años 40 por parte de la Obra Sindical del Hogar. Este ámbito de la ciudad que presentaba unas especiales y preocupantes condiciones de degradación física y conflictividad social ha sido completamente transformado a través de un ambicioso proyecto de renovación urbana que ha recibido diversos elogios y distintivos por parte de distintas Universidades Europeas.

PALABRAS CLAVE: Plan de Vivienda; Área de Reforma Urbana; Simancas; Gandía; Regeneración de la ciudad.

Recibido: 30.09.2019; Revisado: 20.04.2020

Correo electrónico: jorgehervasmas@gmail.com; Nº ORCID: https://orcid.org/0000-0002-8303-0752

El autor agradece los comentarios y sugerencias realizados por los evaluadores anónimos, que han contribuido a mejorar y enriquecer el manuscrito original. 


\title{
Gandía: from the Simancas neighbourhood to the Xocolateres Square. An example of urban regeneration within the framework of the national Housing Plans
}

\begin{abstract}
Gandía has become one of the clearest and most relevant referents in the processes of urban regeneration and revitalization recently managed throughout Spain. In fact, the ducal city that already had a remarkable experience in the management of Integral Rehabilitation Areas ( 500 houses of the Porta Group) or in European Funds destined to the reform of vulnerable neighborhoods (Urban Program III in the neighborhoods of Beniopa, Santa Ana and Plaça Elíptica) now obtains an excellent result in the Urban Renewal Area of the neighborhood known as Simancas. The article therefore deals with an analysis of the actions carried out by the City Council of Gandía, together with the Generalitat Valenciana and the Ministry of Public Works within the framework of the national Housing Plans to renovate one of the most vulnerable areas and disadvantaged of the city. The comprehensive renovation has been carried by the instrument of a Regeneration and Urban Renewal Area Plan (ARRUS), including a 106-dwelling real estate complex built in the 19505 by the Obra Sindical del Hogar. This area of the city - that presented special and worrying conditions of physical degradation and social conflict- has been completely transformed through an ambitious urban renewal project that has received enormous praise and distinctions from different European Universities.
\end{abstract}

KEYWORDS: Urban regeneration; Rehabilitation; Housing reform; Vulnerable neighborhoods; Financial grants; Gandia; State Housing Plan.

\section{Orígenes del Barrio de Simancas en Gandía. La vivienda en el periodo de reconstrucción (1939-1945). El final de la guerra civil y el inicio de la autarquía}

bviamente, el nombre de la promoción de nuevas viviendas en Gandía, no es casual y, como siempre y durante aquella época, obedece a una de las alegorías propuestas por la doctrina del régimen para elogiar los hechos históricos más relevantes del alzamiento militar. En este caso y como en muchos otros, el periodo de autarquía pretendía enaltecer la resistencia "heroica" de los militares del bando nacional sublevados en el cuartel de Simancas en Gijón contra la reacción del ejercito republicano.

Coetáneo en el tiempo, uno de los barrios más castizos de Madrid adoptaría el mismo nombre. De hecho, la relación de Gandía con Madrid desde mediados del Siglo $X X$ es indiscutible, especialmente cuando el negocio del turismo y el ladrillo emergían con fuerza en las playas valencianas. Con la construcción de Gandía se extrapolaría a pequeña escala este Barrio de Simancas (San Blas-Canillejas) de Madrid que fue objeto de una atención especial a través del Plan de Urgencia Social de 1957 que permitió acometer la construcción de centenares de viviendas en la capital.

Por tanto, y al igual que en Madrid, la promoción del Barrio de Simancas de Gandia, construido en la década de los años 50 , se realizó en el ámbito de las políticas urbanas promovidas por la Obra Sindical del Hogar (OSH) Organismo público dependiente y brazo ejecutor del Instituto Nacional de la Vivienda (INV) con el objetivo de fomentar un acceso económico a la vivienda.

Fundada el 10 de diciembre de 1939, la OSH nacía con el objetivo de intentar solucionar el problema de la vivienda mediante la construcción y administración de viviendas de construcción pública, que luego se vendían a bajo precio (UREÑA, 1979).

La promoción de Simancas de Gandía se estructuró en este contexto, en el propio marco de la Ley de 15 julio de 1945 dentro del «Plan Sindical de la Vivienda, Francisco Franco» que se desarrolló en sucesivos programas anuales, con una media de 20.000 viviendas anuales a construir para trabajadores de la Organización Sindical (OS), en colaboración con el INV.

En realidad, la promoción ofrece más bien la impresión de obedecer a iniciativas locales, puntuales y dispersas que permiten justificar, en algunos casos, y a posterior, los planes previstos (MOYA, 1997).

En aquel tiempo las relaciones del INV con las Corporaciones Locales (Diputación, Ayuntamientos, Comisiones de Urbanismo) se limitan a un acuerdo para la promoción de polígonos según el cual, las primeras expropiaban los terrenos por vía forzosa -tras la declaración de construcción urgente- y los cedían a la OSH para su urbanización y edificación. (PEÑIN IBÁÑEZ, 1978). 


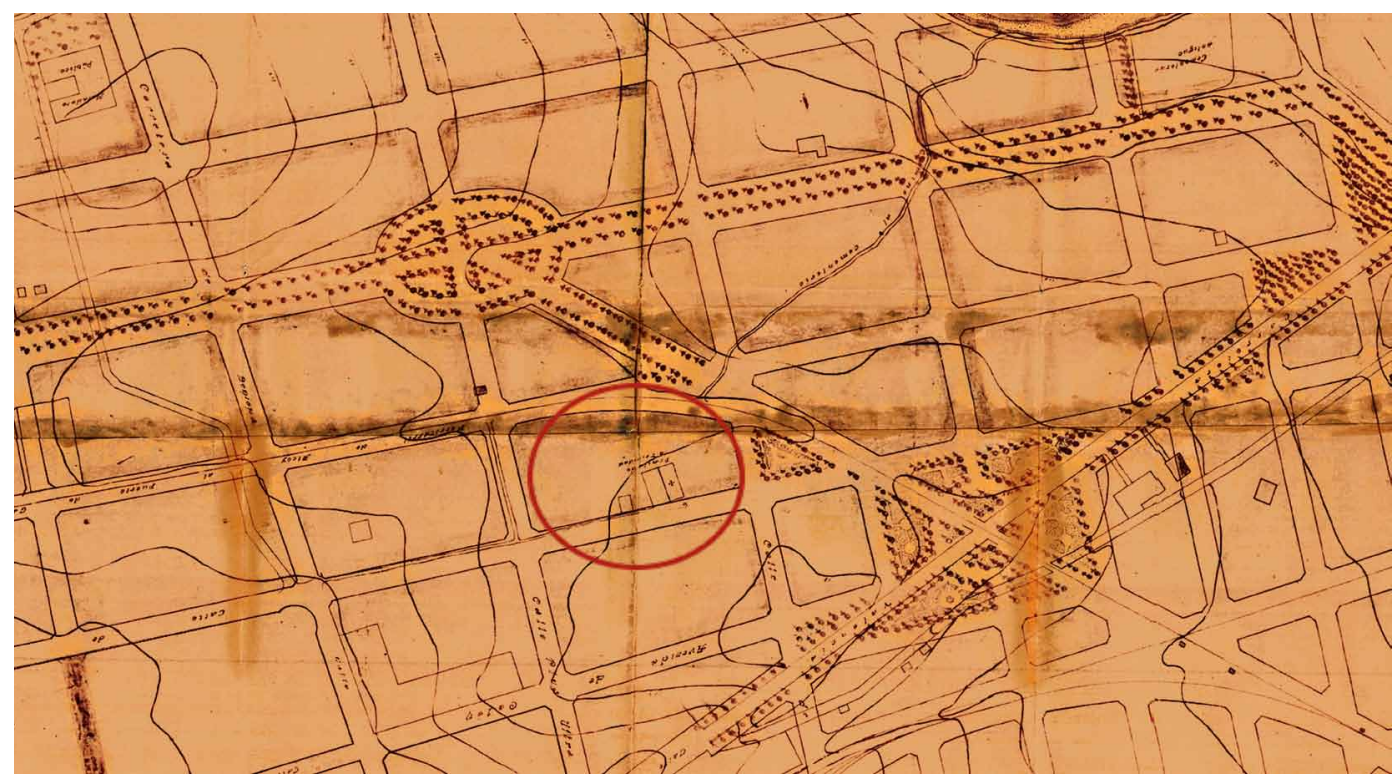

FIG. 1/ Plano ensanche de Gandía 1929. Arquitecto José Pedrós.

Fuente: ARCHIVO BORJA \& MONRABAL.

\section{El emplazamiento de la promoción. Una ubicación singular con un propietario más singular todavía}

Por lo que se refiere a este apartado, el emplazamiento de estos polígonos de viviendas, tampoco solían cumplir ni el planeamiento existente, ni sus operaciones acataban los trámites impuestos por la Ley (normalmente se edifican polígonos sin la redacción del necesario plan parcial).

Los terrenos escogidos por la OSH para sus operaciones solían ser alejados de los centros urbanos y desligados del territorio donde actuaba, siempre con calificación de suelos rústicos para pagar bajo precio por ellos y apropiarse de las plusvalías que se derivarán más tarde del crecimiento de la ciudad. (Del Águila Garcia, 1973).

Normalmente se buscaba para ello terrenos ya situados claramente en la periferia del continuo urbano, apoyados sobre caminos situados en las periferias o en ejes circulatorios.

La promoción del barrio de Simancas (1953) escapó, no obstante, a este modelo de asentamiento. La ubicación se realizó en suelo rústico, pero en un ámbito adyacente al suelo urbano, en una zona de extensión o de ensanche de la ciudad, ya prevista en su Plano de alineaciones y proyectos de ensanche de 1929 y con cierta conexión y continuidad con el suelo urbano.

Por tanto, el emplazamiento se encuentra relativamente contextualizado con la trama de la ciudad y aprovecha la red de caminos o las infraestructuras lineales estratégicas existentes en la Gandía de mediados del Siglo XX. Por una parte, la calle San Rafael, que responde al primer ensanche de Gandía y que superaba, por primera vez, en dirección poniente la muralla del Siglo XV de San Francisco de Borja. En la misma calle y después de su traslado desde los primeros obradores y talleres artesanales situados en frente del Palacio Ducal, la reciente instalación, en el año 1943, de la fábrica de chocolates de Nogueroles en una parcela de $6.000 \mathrm{~m}^{2}$ que costó a la familia de origen de Villajoyosa "a duro el palmo".

Esta industria chocolatera referente en España en los años 50 , conviviría durante mucho tiempo con las 104 viviendas del grupo Simancas. A lo postre, diversas familias vecinas del barrio, especialmente mujeres fueron contratadas en las labores de preparación del cacao. 


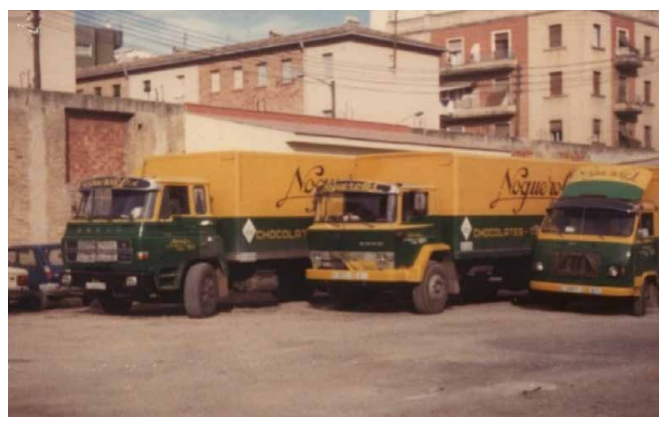

FIG. 2/ Parking industria Chocolates Nogueroles con vistas al complejo Simancas. Año 1974.

Fuente: Archivo BoRJA \& MonRABAL. Gandia.

Por otra parte, la construcción lindaba por el oeste con la línea del Ferrocarril Gandía-Alcoy y apenas unos metros y en dirección Norte con el camino de acceso a la por entonces independiente población de Beniopa.

Concretamente, la OSH se decide por una parcela de $8.000 \mathrm{~m}^{2}$ en la partida de Benissuai, (también llamada Benisnay o de los Hijos de Benisnay) un ámbito situado al Sureste de la ciudad, relativamente cercano al suelo urbano y de alguna $u$ otra forma vinculado a los servicios urbanísticos de energía eléctrica, alcantarillado y suministro de agua potable.
Respecto a su trazado el barrio de Simancas incorporó algunos elementos racionalistas como son la segregación de usos, agrupación de edificios en grandes manzanas que contienen en su interior espacios libres y cierta segregación del tráfico rodado y el peatonal. No obstante, la incidencia de este esquema teórico en la situación urbanística de Simancas en Gandía es insignificante; los factores dominantes hay que buscarlos en las obras de urbanización y la carencia de equipamientos (como factores internos) y la marginación respecto a sus relaciones con los barrios circundantes y la ciudad en general.

El equipamiento comercial es prácticamente nulo, y decimos prácticamente porque en proyecto de ejecución rectificó la portada del expediente administrativo e incluyó escrito a mano y a lápiz "una tienda" aunque esta nunca se llegara a construir.

De hecho y aunque los bloques de Simancas contaban con el propio mercado de la ciudad, el camino a recorrer para llegar a él impedía cualquier tipo de relación. Esto es una consecuencia clara de la segregación de los usos vivienda-comercio y la inhibición por parte de los responsables de tratar de buscar una heterogeneidad en los mismos que fortaleciera la autonomía y funcionalidad de este tipo de barrios.

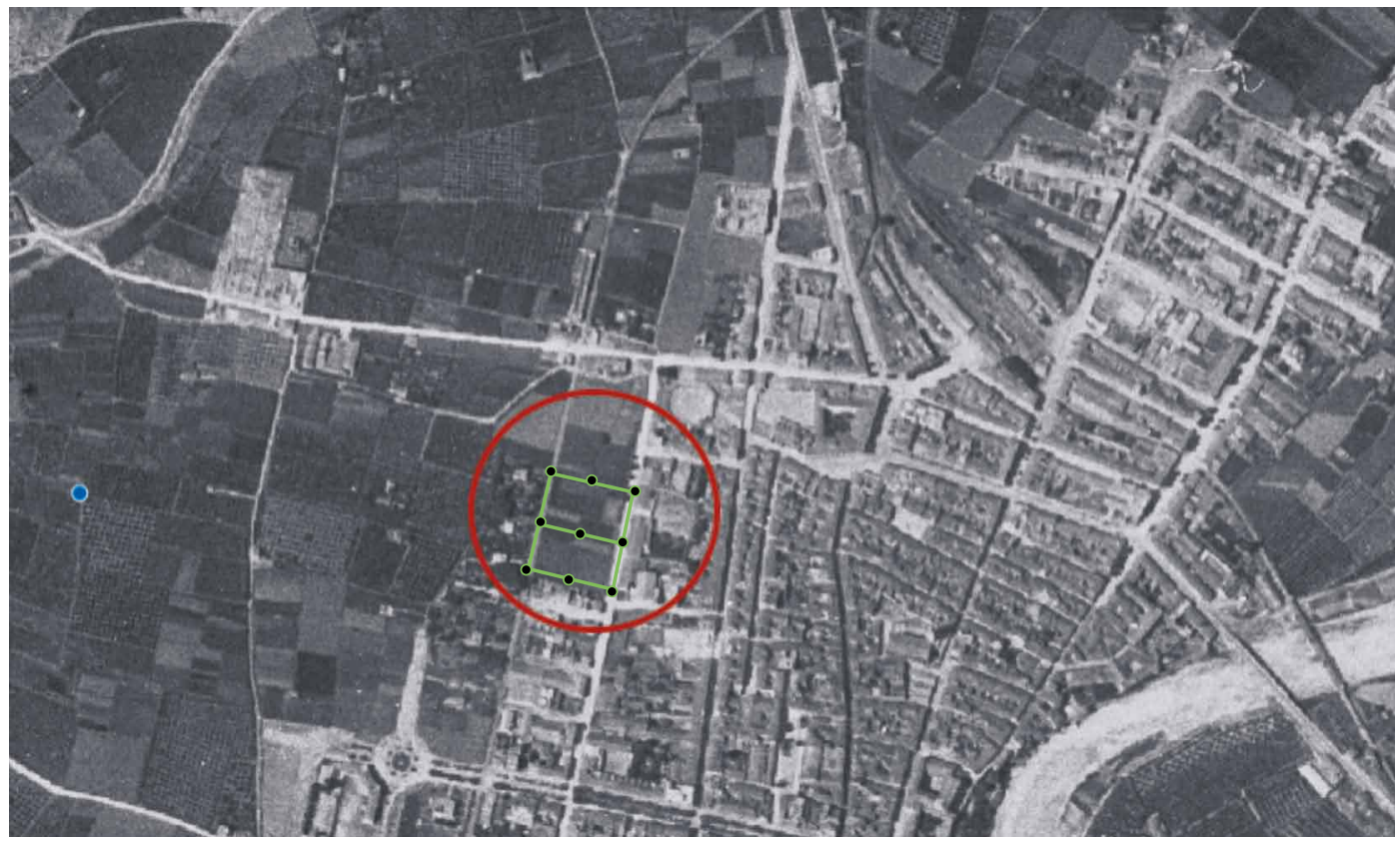

FIG. 3/ Situación parcela de $8.000 \mathrm{~m}^{2}$ Partida de Benisuai. Vuelo americano 1945.

Fuente: Fototeca. Instituto Geográfico Nacional. Ministerio de Transportes. Movilidad y Agenda Urbana. 


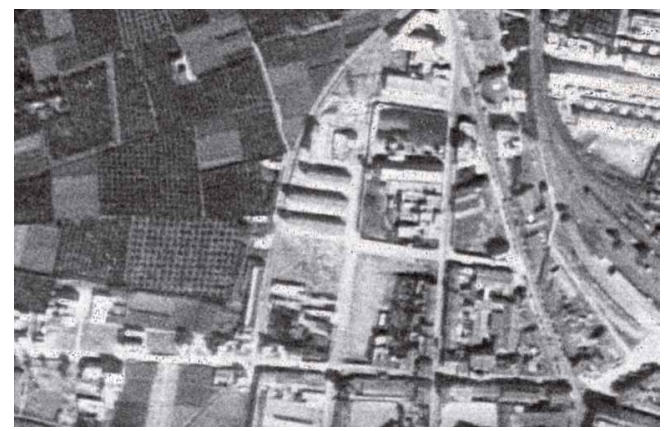

FIG. 4 / Vuelo americano 1956. En el círculo los 4 bloques del Grupo Simancas. A la derecha fábrica de Chocolates Nogueroles.

Fuente: Fototeca Instituto Geográfico Nacional. Ministerio de Transportes, Movilidad y Agenda URBAna.

Mayor interés si cabe, respecto del emplazamiento, merece conocer el propietario de las tierras en las que el Ministerio de la Vivienda propone construir la promoción. De hecho, las parcelas son propiedad de Luis Vallier y García Alessón, a la sazón, Marques González de Quirós, que por entonces disponía de un amplio patrimonio en la comarca de la Safor.

De hecho, no era infrecuente que tanto el INV como a OSH se fijaran, casi siempre en terrenos de la nobleza.

Por ejemplo, años más tarde y después de la gran riada de 1957, la construcción del Barrio de la Merced en Paterna se realizaría en los terrenos de Enrique Gómez Trenor (Conde de la Vallesa y de Montornés) y Eulogio Gómez Trenor. Lo mismo ocurrió en la Barrio "Virgen de la Paloma" de Torrent que daba nombre a Paloma Aguilar, esposa del anterior.

La transmisión de los terrenos de los Vallier, la realizan con fecha de 29 de julio de 1946, sus mandatarios verbales, los hermanos Miguel Caro Valenzuela y José Caro Valenzuela, con distinta relación profesional con Serrano Suñer.

La operación resulta curiosa, ya no por la excepcionalidad del propietario sino también por las condiciones de la adquisición. De hecho, en la mayor parte de las ocasiones la obtención de la propiedad por parte tanto del INV como por parte de la OSH se realizaban a través de la expropiación forzosa del suelo, siempre con tasaciones muy favorables para el Estado.

Sin embargo y en este caso, la operación urbanística del suelo de Simancas se realiza mediante un contrato de compraventa, con una particularidad: de los $8.000 \mathrm{~m}^{2}$ que forman la

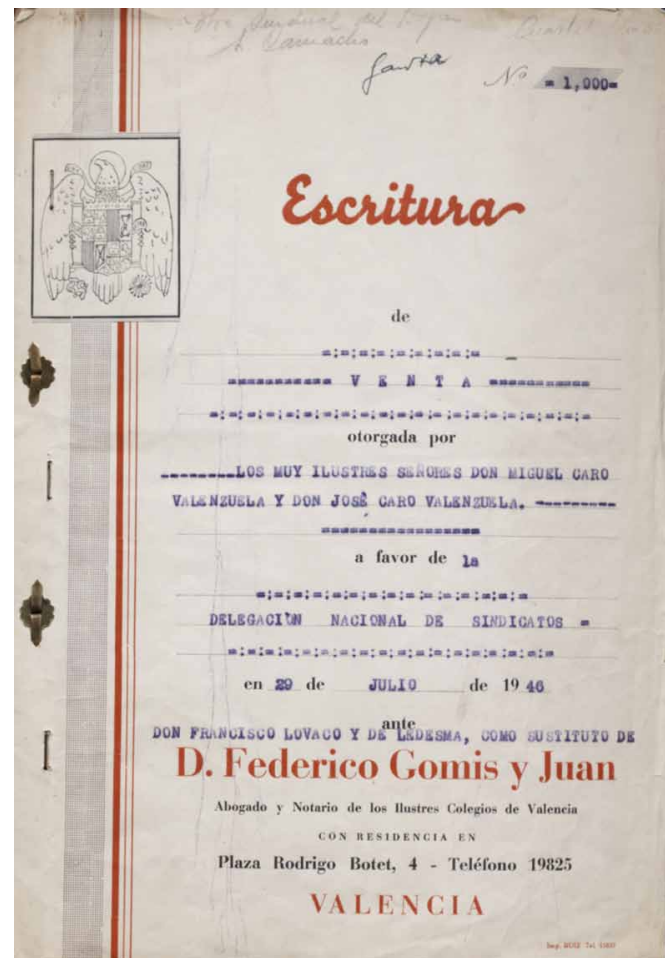

FIG. 5/ Copia escritura de adquisición de los terrenos. 29 de julio de 1946.

Fuente: ArChIVo HISTÓRICO DE GANDÍA

parcela a transmitir, 5.507 son adquiridos por el Ministerio a un precio de tasación de 6 ptas $/ \mathrm{m}^{2}$ mientras que el resto de $2.493 \mathrm{~m}^{2}$ "se regalan" (sic) por el Marqués a este organismo.

Aunque la propuesta que formula la Junta Provincial utiliza la expresión "regalar", desconocemos si los $2.493 \mathrm{~m}^{2}$ formaban parte de una donación en favor de la Obra Sindical del Hogar en toda regla, o por si lo contrario se referían al suelo derivado de las cesiones obligatorias y gratuitas de zonas verdes y espacios libres propios de cualquier actuación de este tipo, incluso con anterioridad a la Ley del Suelo de 1956.

Por otra parte, el resto de obstáculos iban resolviéndose sin esfuerzo. De hecho, la habilitación del solar necesitaba de la demolición de uno de los ejemplos más claros y característicos de la arquitectura religiosa de la ciudad. De esta manera, la antigua ermita de "La Trinidad", es finalmente derribada y sin razón el expediente es silenciado claramente en todos los documentos administrativos y notariales del Ministerio, utilizando siempre el eufemismo "construcción existente". 


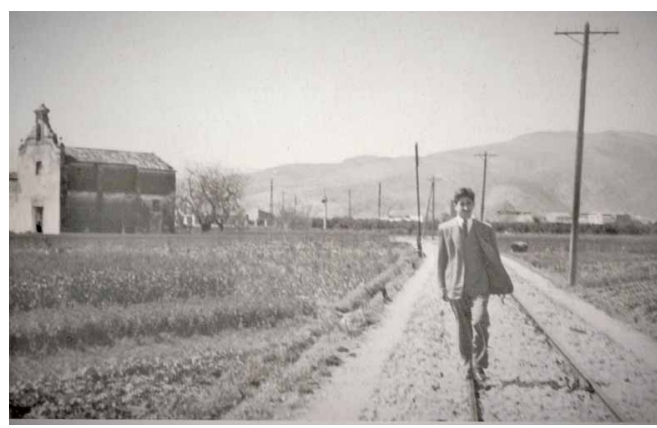

FIG.6/ Vista de la ermita de La Trinidad desde las vías del tren ferrocarril de Alcoy.

Fuente: Archivo. BorJa \& MonRABAL. Gandia

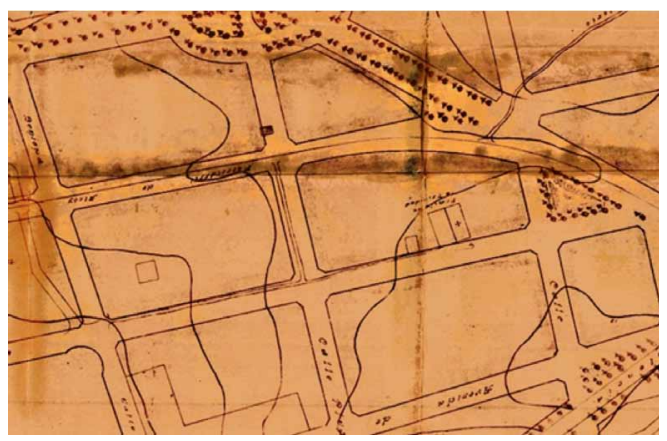

FIG.7/ Ubicación de la ermita de La Trinidad. Plano José Pedrós. 1929.

Fuente: ARCHIVO HISTÓRICO DE GANDIA.

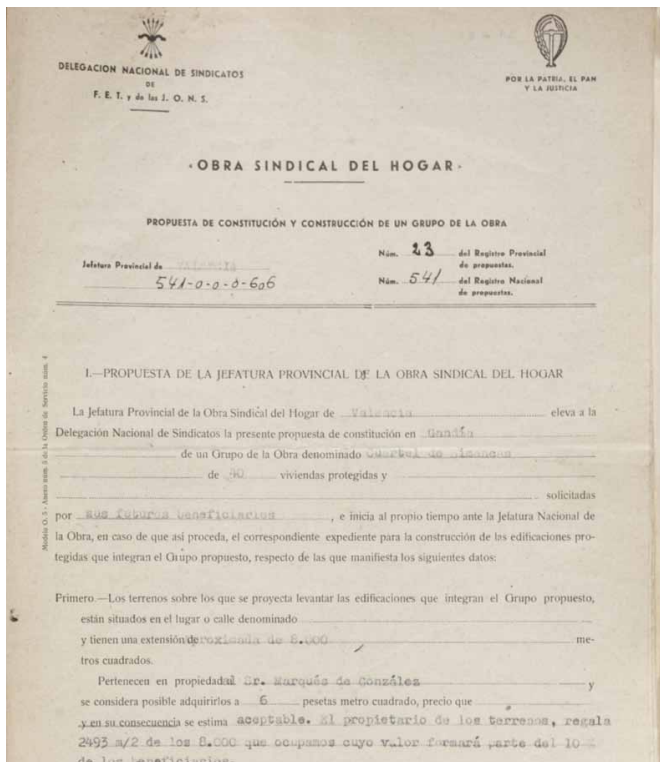

FIG. 8/ Propuesta de la Junta Provincial de Valencia a la Delegación Nacional de Sindicatos.

Fuente: ARCHIVO HISTÓRICO DE GANDIA.

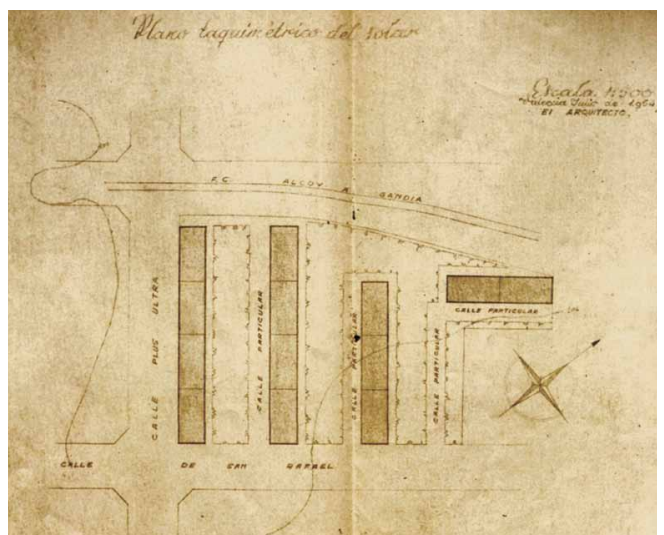

FIG. 9/ Plano de ordenación Barrio Simancas.

Fuente: Archivo municipal Ayuntamiento de Gandia. 1964.

\section{El proyecto constructivo y el inicio de las obras}

La actuación fue aprobada por el Ministerio de Obras Públicas, el 23 de agosto de 1943, acordándose la financiación de la actuación y emplazándose al arquitecto responsable para la elaboración de un anteproyecto en un plazo de 45 días. Finalmente se decide contratar al Arquitecto Municipal del propio Ayuntamiento de Gandía, Pablo Soler y al arquitecto Luis Costa Serrano que ya disponía de distinta experiencia en diversas promociones previas gestionadas por la Obra sindical en distintos municipios valencianos.

La actuación se ralentiza durante un periodo dilatado de tiempo por problemas burocráticos, reactivándose de forma definitiva por la Obra Sindical del Hogar en julio de 1954, disponiendo de un presupuesto de $4.538 .872,18$ ptas. Asimismo y para la financiación de la promoción el Ministerio contrata un préstamo de 640.037 ptas. por un plazo de veinte años.

Las obras son licitadas a través de un procedimiento restringido por la Delegación Provincial del F.E.T. y de las JONS a la que solamente se presenta una empresa aspirante, Vicente Montesinos Fernández, constructor de Valencia que aporta como méritos la construcción del Hotel Excelsior en la ciudad de Valencia, por el propio tipo de licitación y sin formular baja económica alguna.

Simancas reprodujo al milímetro el patrón de los grupos de viviendas de la OSH, también llamados popularmente «bloques caracol», en honor a sus estrechas escaleras. Construcciones racionalistas con apenas motivos decorativos, de corte clásico, a cuatro alturas y jardín o patio central, de carácter residual, que al mismo tiempo hace las funciones de viario interior. 


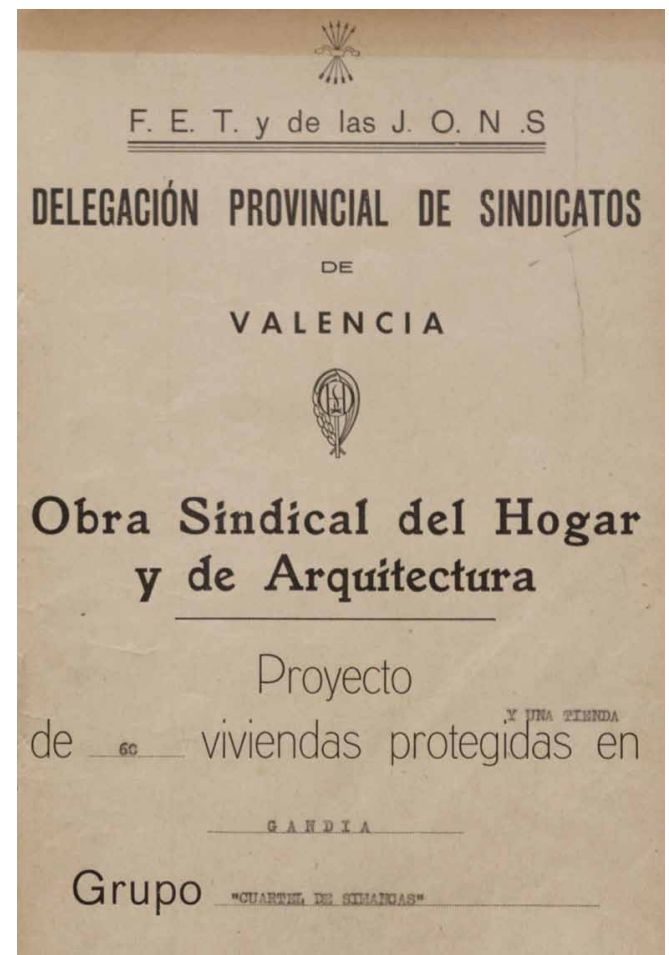

Fig. 10/ Proyecto básico aprobado el 23 de agosto de 1943.

Fuente: Archivo municipal Ayuntamiento de Gandia.
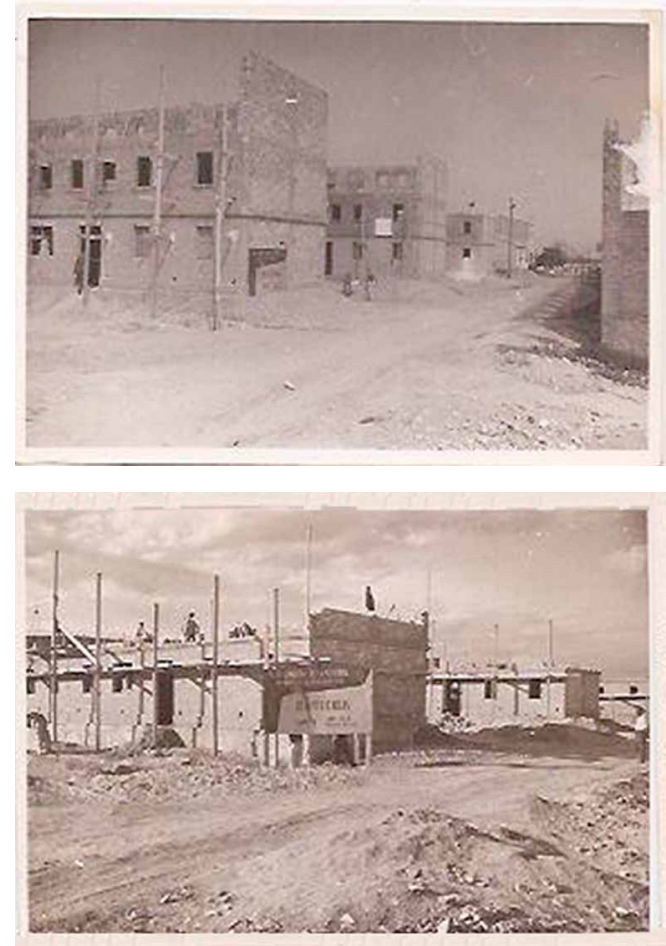

FIG. 11 y 12/ Inicio del proceso constructivo $\mathbf{1 9 4 5 .}$ A la derecha la fábrica de chocolates Nogueroles.

Fuente: ARCHIvo Suso MonRABAL.

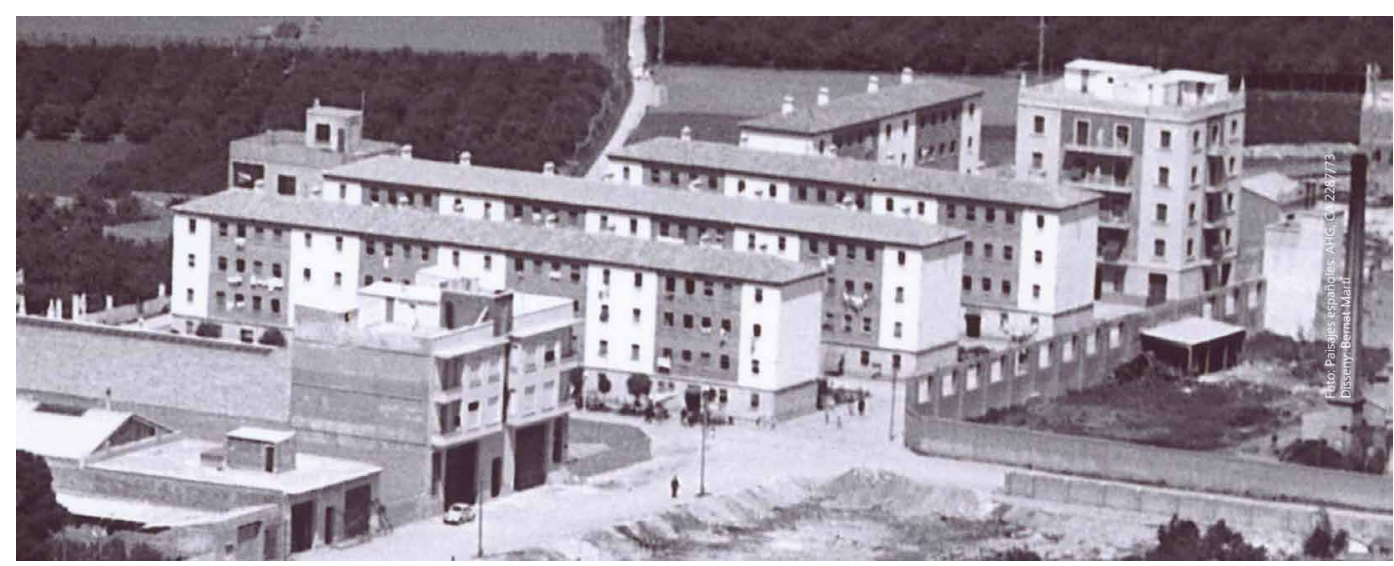

FIG.13/ Finalización de las obras. Año 1950.

Fuente: ARchivo HISTÓRICO DE GANDIA.

El conjunto estaba subdivido en cuatro grandes piezas exentas que conforman un grupo unitario; todos ellos con cuatro plantas de altura. El conjunto estaba formado por 13 bloques que a 8 viviendas por escalera determinaban un total de 104 viviendas. Asu vez, las viviendas, estaban compuestas por tres dormitorios, un comedor-estar, un vestíbulo, una cocina y una ducha y lavabo. Se desarrollaron en doble crujía lo que permitió que todas las habitaciones, excepto los baños, fueran exteriores, proporcionando un agradable conjunto y una absoluta independencia de las viviendas (Mut, 1997).

Las obras finalizan en julio de 1957, suscribiéndose el acta de recepción y procediéndose a la devolución de la garantía definitiva. 


\section{Las características de las viviendas}

El proyecto de las viviendas está desarrollado en cuatro tipos concebidos a partir de un organigrama único. El programa es el mismo que el de las viviendas convencionales, es decir, la vivienda incluye, como se ha dicho supra, vestíbulo, comedor-estar-cocina, dos o tres dormitorios, aseo sin terraza, pero todo ello en una superficie a todas luces insuficiente para permitir su correcto funcionamiento (BLAT, 2000).

Es evidente que la OSH intentaba con este programa dar la apariencia de satisfacer la aspiración de dotar a los trabajadores de hogares dignos y alegres y la forma de llevarlo a la práctica era incluir en él los elementos más representativos de la vivienda burguesa. Por otra parte, la normativa dictada especialmente por el Instituto Nacional de la Vivienda para los hogares de Renta mínima, toleraba la reducción a $14 \mathrm{~m}^{2}$ del mínimo de superficie de la estancia, supresión de la limitación de altura de techos y mínimo de cubicación a los dormitorios, exigiendo únicamente para éstos la representación en los planos de las camas previstas. De hecho, dicha normativa entraba en abierta contradicción con las demás vigentes en aquella época, entre ellas las ordenanzas sobre condiciones higiénicas mínimas del año 1944 (LASo dE LA VEGA, M. 2020).

A esto último hay que añadir que estas viviendas no solamente resultan inadecuadas debido a las nuevas necesidades que se fueron creando con el paso del tiempo, sino que incluso en su época estaban por debajo de las exigencias consideradas mínimas y básicas de habitabilidad.

De hecho, fue muy difícil encontrar en el año 2007 , momento en el ayuntamiento inicia la reforma del Barrio de Simancas, una vivienda que se mantuviera con las mismas condiciones que la OSH la entregó, por cuanto que la mayoría de los vecinos no tuvieron otro remedio que realizar importantes transformaciones. De hecho, es interesante observar que el volumen de las obras de modificación realizadas por los vecinos siempre estuvo en proporción inversa al número de hijos, lo cual quiere decir que existe un cierto paralelismo entre el nivel económico de la familia y la cantidad de modificaciones, mejoras y reparaciones llevadas a cabo en la vivienda.

\section{Adjudicación de las viviendas}

Una vez ejecutado el proyecto y recibidas las obras por el INV, llegaba el momento de adjudicarlas a los vecinos gandienses.

De hecho y en todas las promociones referidas a los Planes de Viviendas sociales de la autarquía el procedimiento solía ser único. En primer lugar, la Jefatura Nacional de la OSH, a propuesta de las Ponencias de Utilización de los Patronatos

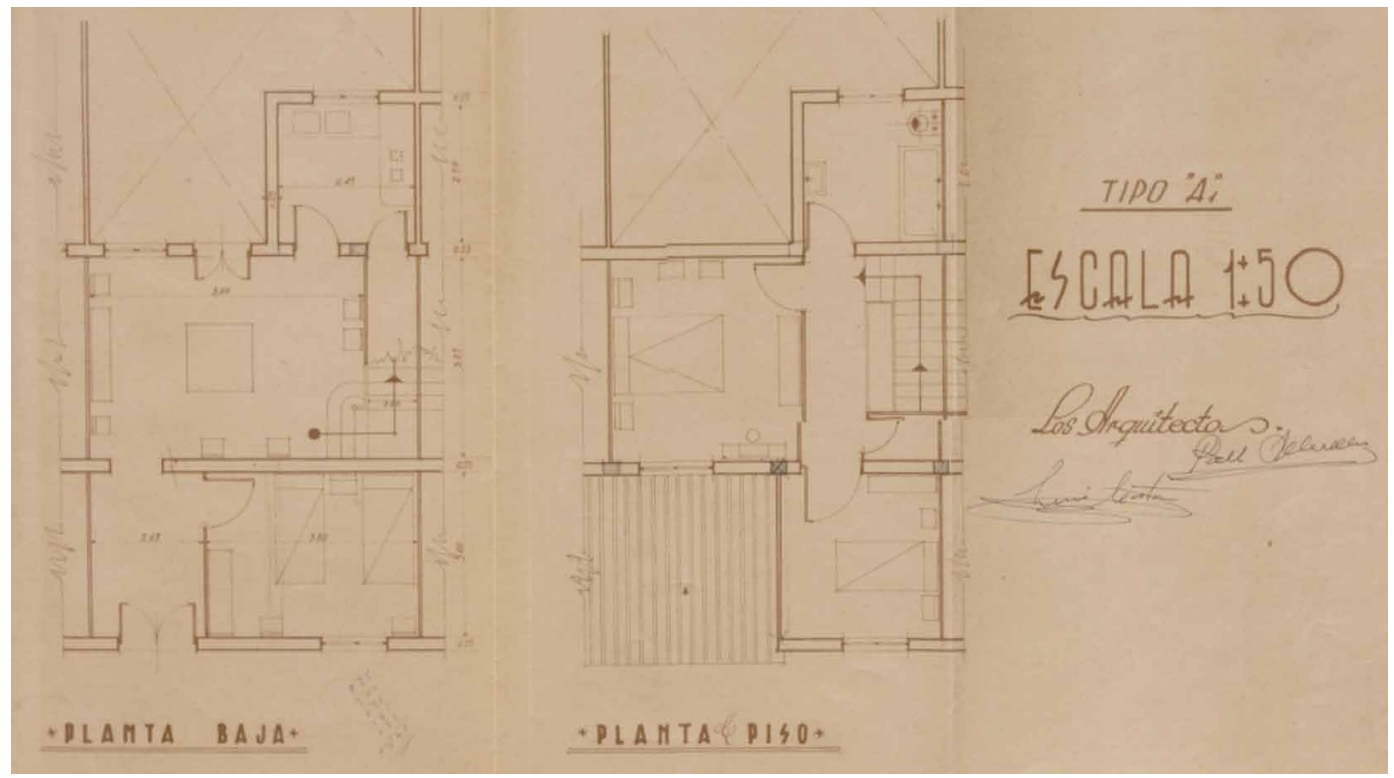

FIG. 14/ Plano de detalle. Características de las viviendas.

Fuente: Archivo histórico Ayuntamiento de Gandía. 
Sindicales Provinciales, determinaba anualmente las viviendas objeto de la distribución.

Después de reservarse la OSH. algunas viviendas para organismos oficiales, adjudicaba un número determinado al propio Organismo Estalal y a los Montepíos y Mutualidades Laborales que las distribuyen por sorteo, previa formación de listas de solicitudes, entre sus beneficiarios. En esa situación, era condición indispensable estar sindicado y acreditar la falta de habitación (JUBERT, 1974).

El cupo que corresponde a la OSH se distribuía en las primeras promociones de los años 50 en la forma siguiente:

- funcionarios sindicales y del Movimiento.

- excombatientes, excautivos. mutilados, Vieja Guardia, militantes de FET, viudas de Caídos.

- casados en año adjudicación.

- familia numerosa.

- afiliados entidades sindicales

Tras rellenar el modelo de solicitud de Sindicatos y enviado el informe de las Juntas Sindicales al respectivo Patronato se adjudican las viviendas por sorteo para cada grupo, excepto en el de funcionarios que se conceden por escalafón, sin permitir permutas o cesiones.

Esta composición irá variando con el tiempo en función de las demandas y el carácter de las promociones, en el sentido de que el carácter netamente obrero se acentúa progresivamente, y por otra parte desaparecen los grupos destinados a favorecer a determinados sectores sociales afectos ideológicamente al régimen.

Este último es el que parece que se aplicó al caso de Gandía. De hecho, la adjudicación de las viviendas de Simancas se realiza por puro sorteo entre los vecinos de la ciudad, sin que aparentemente se determinasen ni privilegios ni favoritismos.

Se pensó que el grupo Simancas, como así sucedió en muchas ciudades españolas, trataba de absorber el gran contingente de población emigrante que colapsó en los años cincuenta de infraviviendas y chabolismo las zonas de las periferias. Pero en realidad, no fue el caso.

De hecho, Simancas albergó mucha parte de la población del Barrio gandiense conocido como el Raval, un ámbito que atravesaba por aquellas épocas un verdadero proceso de decadencia, abandono y degradación y que invitó a muchos de sus vecinos a marcharse a la "ciudad nueva".

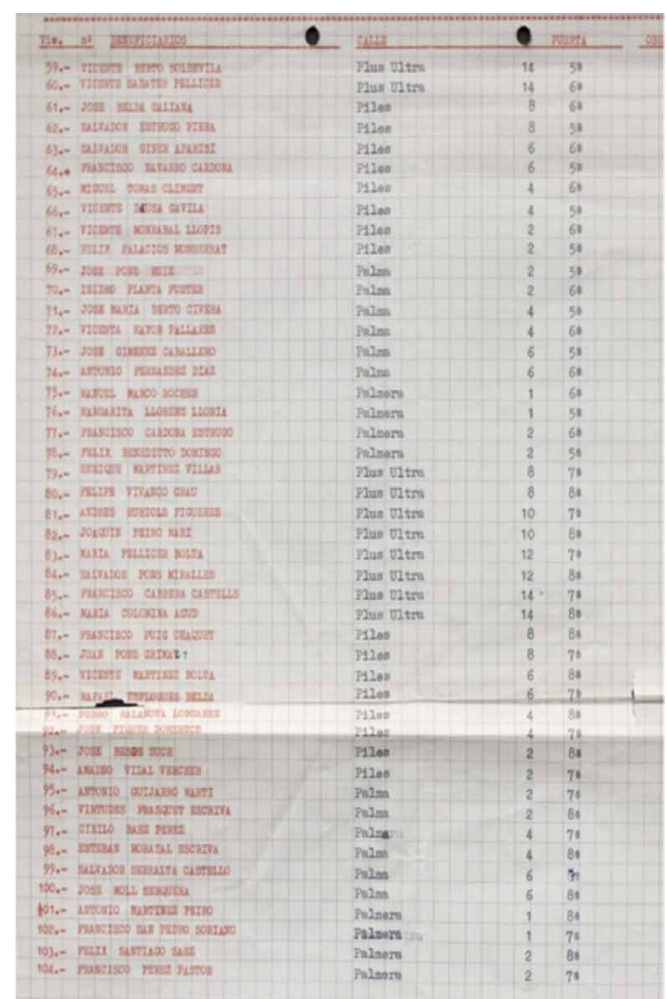

FIG.15/ Listado de adjudicatarios viviendas en Simancas.

Fuente: Archivo Histórico de GandiA.

Incluso esta transferencia de población estuvo siempre presente en los planes del Alcalde José Román Martí en el marco de sus intentos por sanear y oxigenar esta parte de la ciudad.

A ello se sumaba la excelente publicidad y elogios que el Régimen aplicó a la promoción de las nuevas viviendas de Simancas. Y al final, como todo en la vida, venció el interés por sustituir las antiguas casas de pueblo de agricultores y artesanos en favor de los nuevos aires de modernidad de viviendas contemporáneas, aunque pronto se manifestaría justamente lo contrario.

\section{Las viviendas económicas y los primeros desperfectos}

El problema de las viviendas de Simancas no solamente fue de superficies sino también de su calidad constructiva. De hecho, la sencillez y la pobreza los materiales utilizados en su día, se tradujo en la pronta aparición de los primeros desperfectos y patologías en las viviendas por un lado y en el conjunto del edificio por otro. 
Para poder valorar la calidad de la vivienda nada más tenía que observarse los acabados, equipos, instalaciones, sistema constructivo y aislamientos de lo que se puede deducir el gran volumen de obra que debieron realizar los vecinos para acondicionar su vivienda.

a. Colocación de elementos inexistentes en la vivienda de origen (equipos para la instalación eléctrica, agua caliente).

b. Sustitución de elementos que debido a la elevación del estándar de vida no pudieron cubrir las necesidades de sus propietarios. (sanitarios, mármol en cocina).

c. Sustitución de elementos por envejecimiento (porticones, pavimentos y pintura).

d. Ocultación de desperfectos (grietas y humedades).

e. Reparaciones varias como tuberías y goteras.

De ello se deduce que en la vivienda de origen faltaban muchas cosas y que otras muchas eran defectuosas o no pudieron resistir el paso del tiempo.
En muchas ocasiones los vecinos no pudieron reparar estos desperfectos como convendría y su acción se limitó ocultarlos. Sin lugar a dudas, fue precisamente la falta de estas reparaciones importantes lo que influyó más en el rápido deterioro de las viviendas.

Esta es sin duda, la experiencia de las mal llamadas "viviendas económicas" (LLORENS, 1974). Económicas, al fin y al cabo, solamente lo fueron para el promotor, pero no para el usuario que tuvo que realizar costosas inversiones para obtener un producto que nunca llego a satisfacer sus mínimas necesidades vitales. (DoLs, 1974)

Al final los bloques de Simancas tuvieron un periodo de duración proporcional a la calidad de su construcción de tal manera que las viviendas de Simancas demostraron pronto su incapacidad de soportar el embate el tiempo. En 1969 y a los pocos años de la entrega de llaves la OSH tuvo que acometer un proyecto de reparaciones extraordinarias por importe de 292.000 ptas. Al final esta intervención y como se verá más adelante, trató más de apuntalar su degradación y frenar su abandono que de devolver el inmueble a sus mejores condiciones.
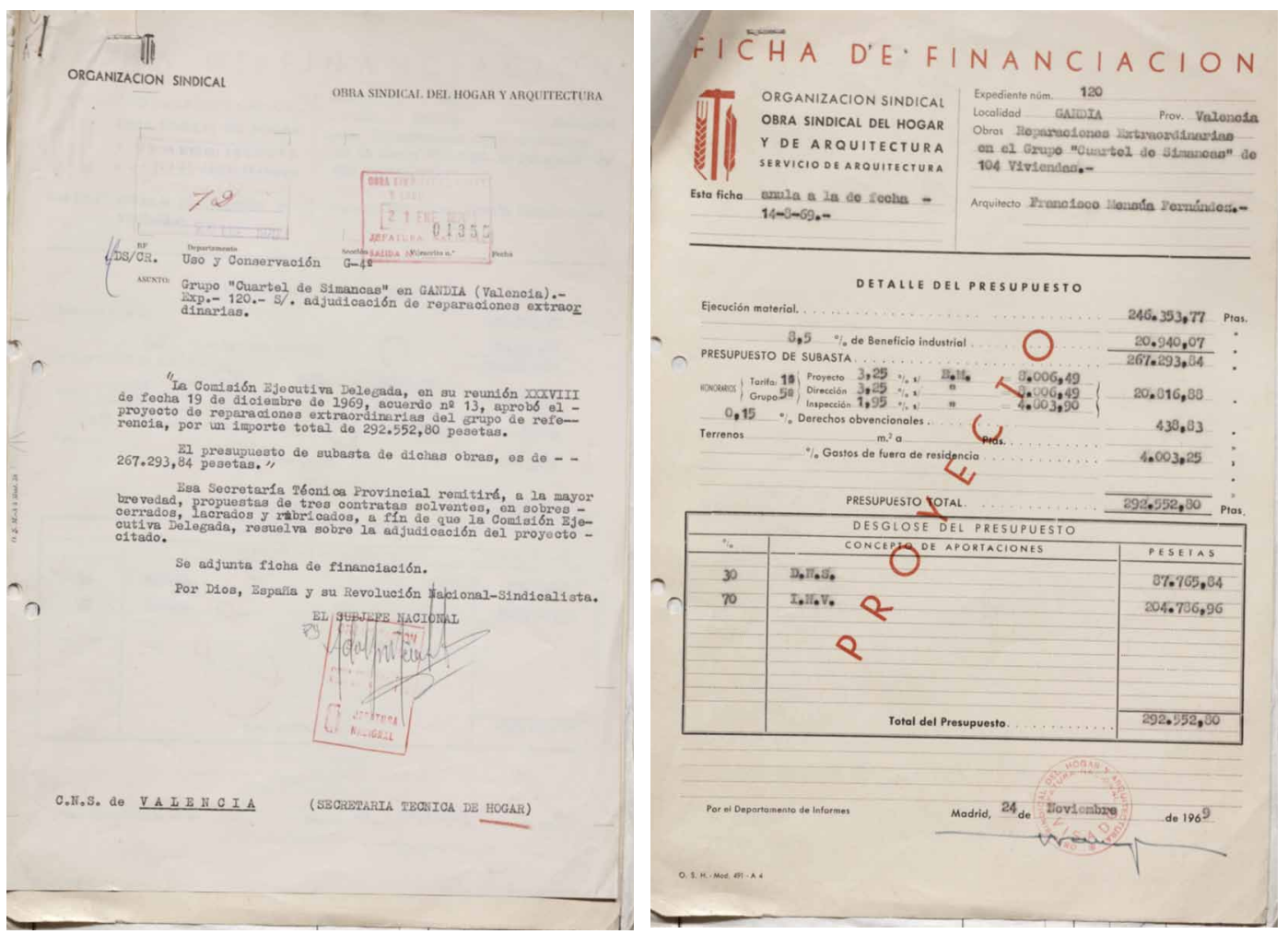

FIG. 16 y 17/ Autorización y Proyecto de reparaciones extraordinarias 1969.

Fuente: Archivo Histórico de Gandia. 


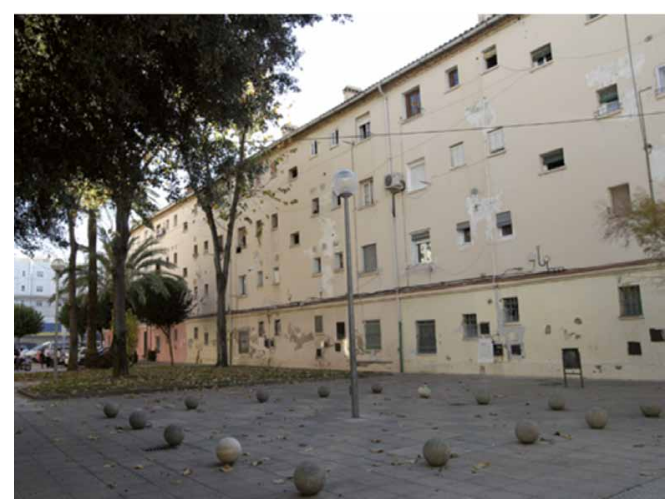

FIG. 18/ Barrio de Simancas. Año 2007.

Fuente: ARchivo HistóRIco de GANDIA.

\section{El periodo 2002-2007. La absoluta decadencia del Barrio de Simancas}

A los cincuenta años de su construcción, y justamente inaugurado el Siglo XXI, el Barrio de Simancas entra definitivamente en un proceso de decadencia y cae absolutamente en barrena.

Por una parte, se constatan los efectos urbanísticos de un espacio urbano totalmente degradado, en el que se diagnostican serios problemas de conservación y seguridad y en el que se suceden continuos requerimientos y órdenes de ejecución procedentes del Ayuntamiento sobre la seguridad del edificio que son desatendidos sistemáticamente por sus propietarios.
A su vez, esta crisis urbanística cristaliza en un evidente declive social del barrio que se manifestó en un progresivo envejecimiento de la población, la presencia de una alta tasa de emigración y la ocupación clandestina de viviendas.

A ello, se sucedieron los primeros problemas de convivencia, la concentración de la problemática social, el tráfico de drogas, un incremento significativo de la criminalidad y en pocas palabras la formación de un auténtico gueto en una de las mejores zonas del centro urbano de la ciudad.

La antigüedad de la edificación y sus deficientes condiciones de funcionamiento hace que los originarios propietarios de Simancas fueran sustituidos por segmentos de población con escasos recursos económicos y por grupos con modelos de comportamiento muy diferenciados de los primeros propietarios, mediante alquileres, o en ocasiones, ocupaciones de viviendas sin título (CHECA \& ARJonA, 2008), moradores, todos ellos con escasa preocupación por el mantenimiento y conservación de un edificio «que nos les pertenece» y que no hacen sino que confirmar la movilidad o inestabilidad residencial y en consecuencia la falta de arraigo de los realojados.

Expuesto esto, el Barrio de Simancas incorporaba un paisaje dantesco; una tasa de paro altísima y unos problemas de convivencia insoportables. Esta situación conllevó a que los grupos familiares normalizados fueron desapareciendo progresivamente del barrio, siendo desplazados progresivamente por familias con graves problemas de esestructuración y finalmente por grupos marginales en la sociedad actual.
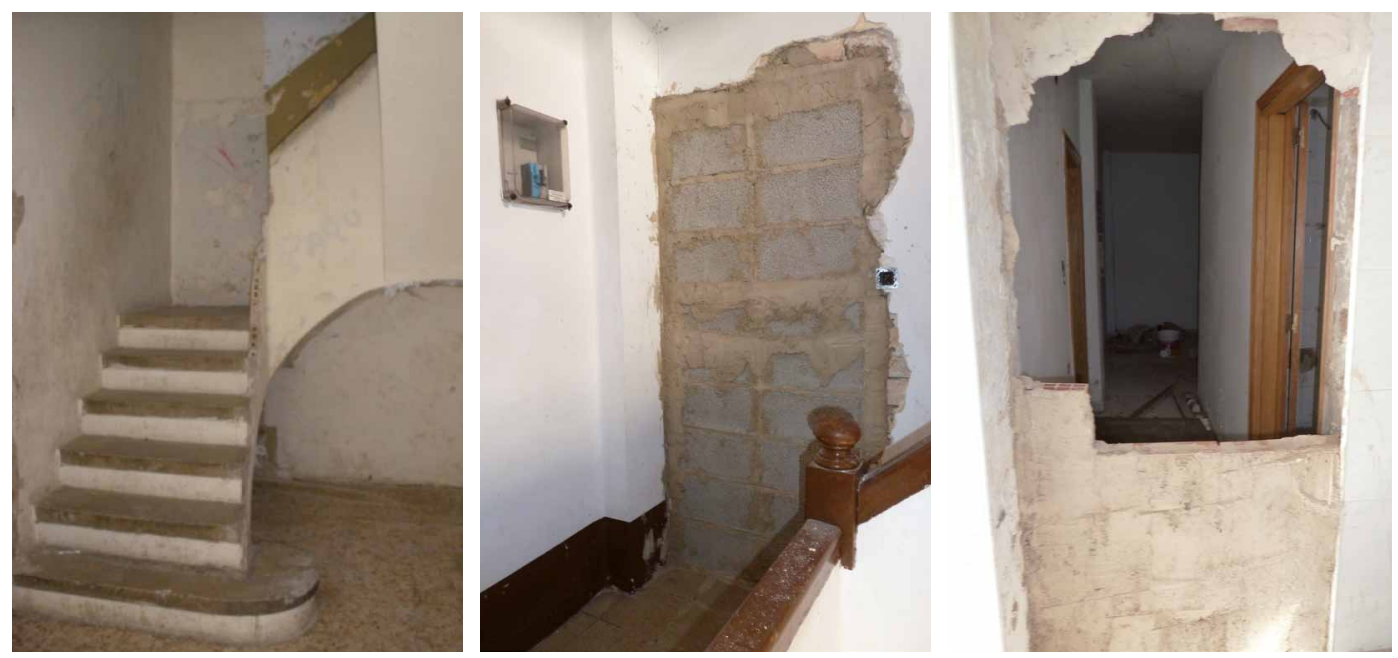

FIG.19, 20 y 21/ Espacios interiores Viviendas Simancas. 


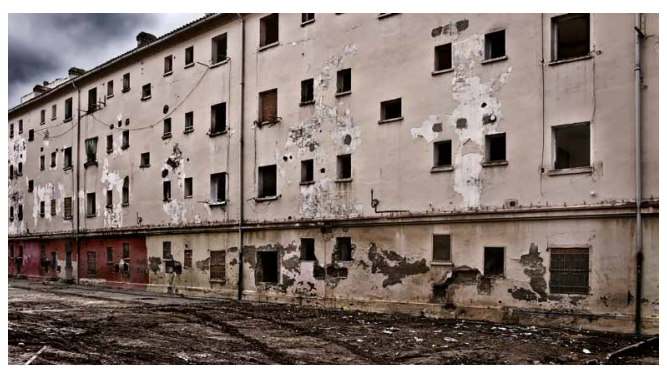

FIG. 22/ Edificio Simancas. Inicio proceso de demolición.

Fuente: Archivo Departamento de Urbanismo Ayuntamiento de Gandia.

El resultado final supuso la consolidación de un núcleo de infraviviendas encerrado en sí mismo, con importantes problemas de marginalidad e integración social, en el que las edificaciones dejaron de ser conservadas adecuadamente, fueron objeto de usos inapropiados y generaron situaciones de auténtica ruina.

En este sentido, el deterioro absoluto de estos espacios operaba como elementos disuasorios de los desarrollos urbanísticos colindantes, todo ello sin olvidar el contagio y degradación de los entornos urbanos más próximos.

Ante esta situación de emergencia en el ejercicio 2007, el Ayuntamiento de Gandía, se pone "manos a la obra" e inicia los trámites tendentes a la declaración de Área de Reforma Urbana y a su consideración como Barrio de Acción Preferente.

\section{El inicio de la rehabilitación. La declaración de ARRUS y las primeras actuaciones urbanísticas}

La situación que presentaba el barrio de Simancas, en el inicio de las actuaciones del Programa respondía a 104 viviendas con importantes déficits de servicios, sin cumplir normas de habitabilidad, sin ascensor y con condiciones de accesibilidad nulas, sin plazas de aparcamiento y con unas condiciones de mantenimiento y conservación extremadamente deficientes. (MUT OLTRA, 1981).

La actuación requería, por una parte, una remodelación integral del espacio público y por otra, una sustitución y renovación completa e integral de las construcciones existentes.

\subsection{El Plan de Reforma Interior}

La situación preexistente del barrio presentaba cuatro bloques exentos de viviendas de planta baja paralelos entre sí con orientación este-oeste junto con un último, perpendicular a los anteriores y en posición Sur. Se diseñaban a partir de viarios internos sin salida junto con reducidas zonas verdes fragmentadas y marginales que de ninguna manera cumplían los estándares de calidad actuales.

Esta regeneración urbana se inició con la preparación de un Plan de Reforma Interior que tuvo como objetivos fundamentales, el mantenimiento de la población existente evitando la gentrificación, la mejora de las condiciones de habitabilidad, la redefinición y mejora del viario, convirtiéndose en zona peatonal y mejorando la superficie de zona verde existente, evitando su fragmentación.

Este Plan de Reforma Interior, mediante una ordenada remodelación de volúmenes, sustituye cuatro bloques por dos, realizándose una transferencia y reparto de la edificabilidad de tal forma que en la nueva ordenación un blo-que dispone de planta baja más cinco y el otro de planta baja más cuatro. Al mismo tiempo, los pequeños jardines residuales se agrupan creando un jardín central y se habilitan varios equipamientos comunitarios. Finalmente se construye, en el subsuelo un aparcamiento comunitario de 350 plazas con objeto dar respuesta a un problema acuciante en el centro de la ciudad al mismo tiempo que servía para viabilizar económicamente la actuación.

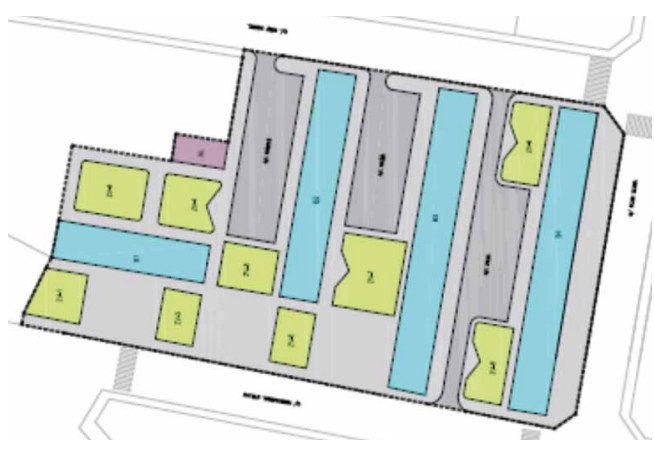

FIG. 23/ Plano de información Simancas. PRI.

Fuente: Archivo histórico Ayuntamiento dE Gandia.

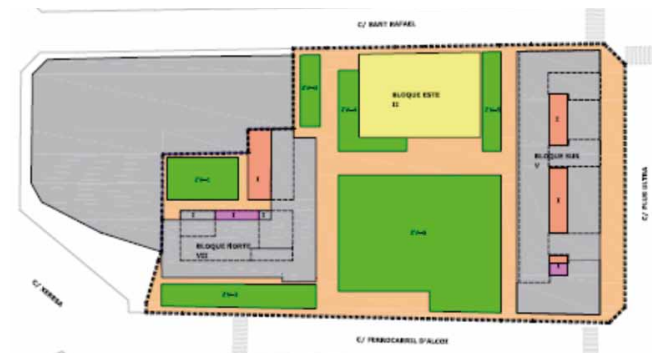

FIG. 24/ Plano de ordenación. Plan de reforma Interior Simancas.

Fuente: Archivo Departamento de Urbanismo del Ayuntamiento de Gandia. 


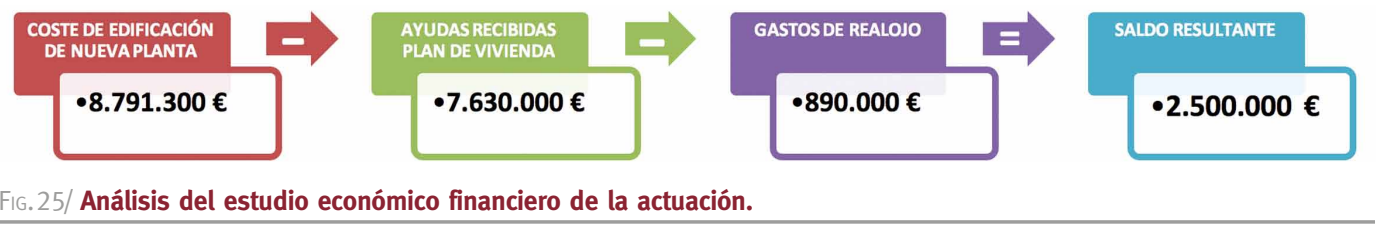

Fuente: Elaboración propia.

\subsection{La participación de \\ los propietarios en el proyecto. La reparcelación horizontal}

Aprobado el planeamiento, se inició la fase de gestión del suelo. En este sentido, la mayor parte de las áreas de regeneración urbana se ha gestionado vía expropiación forzosa (HERVAs, 2017), mediante procedimientos de urgencia, actuación que permite obtener el suelo con cierta celeridad pero que exige importantes adelantos e inversiones económicas.

Sin embargo y a diferencia otros ARRUS, el ámbito de Simancas se gestionó vía proyecto de reparcelación urbanística de carácter horizontal, con el objeto de permitir a los propietarios originales incorporarse al proceso de edificación. En este sentido, se determinaron como fincas de aportación las viviendas iniciales según la correspondiente cuota de participación de conformidad con la escritura de división horizontal, sustituyéndose -vía reparcelación- por las viviendas de resultado previstas en el proyecto constructivo.

La reparcelación horizontal, permitía a los anteriores propietarios el mantenimiento del aprovechamiento previo a la actuación urbanística, entregándoles a la finalización del proceso unas nuevas viviendas totalmente ajustadas a los cánones de seguridad y habitabilidad actuales.

La actuación con un coste de urbanización y edificación cercano a los 9 millones de euros se financiaría por los propietarios mediante el pago de las cuotas de edificación en metálico, en techo edificable o mediante la modalidad mixta.

En este sentido, la cuenta de la liquidación definitiva de la reparcelación se conformaba por el coste de la edificación de nueva planta a la que se deducía las ayudas recibidas por el ARRUS y los costes de realojos y traslados derivados de la actuación.

\section{El proceso constructivo}

EI ARRUS fue gestionado a través de una encomienda de gestión a favor de la empresa pública de capital exclusivo municipal del Ayuntamiento "Iniciatives Públiques de Gandía S. A." que actuó en todo momento como entidad promotora.

Las obras se licitaron en julio de 2010 por un importe total de $8.791 .199,31 €$ y con un plazo de ejecución de 24 meses, siendo adjudicadas a favor de la empresa COESMI SL.

A finales del año 2010 se inician las obras de demolición, y a continuación de forma inmediata las obras de reedificación. Con motivo de la crisis financiera e inmobiliaria del periodo 2006-2011, el Agente constructor COESMI SL es declarado en la situación de concurso de acreedores, hecho que paraliza completamente la ejecución de las obras por más de tres años. Tras este paréntesis en la ejecución de las obras, las mismas se reactivan esta vez en el marco del nuevo Plan Estatal 2013-2016 (RD 233/2013) siendo finalizadas de forma definitiva en junio de 2017.

\section{La financiación del ARRUS. Las ayudas del Ministerio de Fomento y de la Generalitat Valenciana}

Sin lugar a dudas, la renovación de Simancas y ninguno de los ARRUS, actualmente en ejecución en España, se hubiera podido realizar sin el espaldarazo y la ayuda económica del Ministerio de Fomento y la Generalitat Valenciana.

Obviamente la clave de bóveda de todo el entramado de la Rehabilitación Urbana está en su financiación, por cuanto que no cabe duda que estas actuaciones requieren importantes esfuerzos económicos y presupuestarios e inyecciones de capital público sin cuya participación la revitalización de los barrios sensibles y desfavorecidos es nula.

En este sentido, con fecha de 21 de septiembre de 2010 se firmó el correspondiente Convenio de Colaboración entre el Ministerio de Vivienda, la Generalitat Valenciana y el Ayuntamiento de Gandía, todo ello en el marco del Plan Estatal de Vivienda y Rehabilitación 2009-2012. Con posterioridad se firman convenios complementarios en el 2015 y 2016 con motivo de la entrada en vigor de los siguientes Planes Estatales de Vivienda. 
Al final, la inversión total alcanza el importe de 7.127.214 euros con una participación de las distintas Administraciones hasta el importe de 5.798.253 euros y 1.369.994 euros de financiación por parte de los particulares.

\section{Conclusión}

El ARRUS de Simancas se constituye como un punto de inflexión en el modelo de regeneración y rehabilitación de la ciudad preexistente. Gandía ha pasado de un modelo de crecimiento urbanístico expansionista y de consumo del territorio hacia un modelo en el que el protagonista es la ciudad construida.

La gestión de esta actuación no ha estado exenta de dificultades. Se trata de una inversión que ha pasado por tres planes de viviendas 2009-2012, 2013-2016 y 2016-2018, con condiciones de ejecución y financiación muy diferentes de efectos retroactivos y con la sensación de cambios en las reglas de juego a medida que el partido avanza.

Durante este tiempo, las mismas viviendas han llegado a ser de protección pública régimen general, por unos meses viviendas libres, más adelante sujetas al régimen de protección e incluso viviendas sociales, con los quebraderos que esto supone para el Ayuntamiento y sus propietarios.

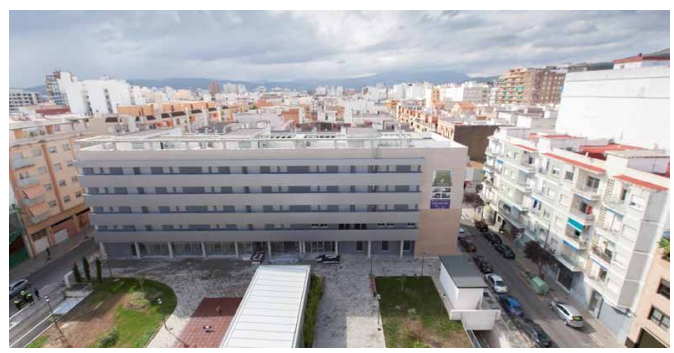

FIG. 26/ Promoción Grupo Simancas. Año 2018.

Fuente: Archivo Departamento de URBanismo del Ayuntamiento de Gandia.

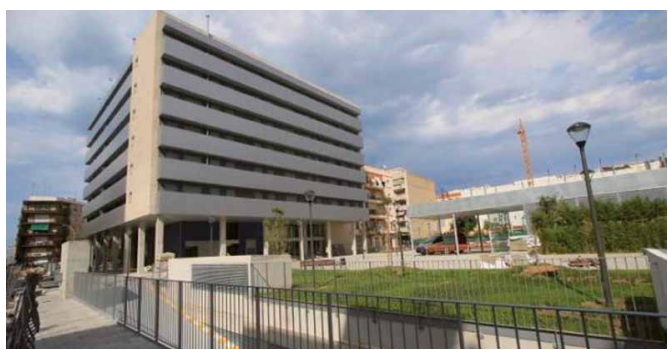

FIG. 27/ Área de juegos y acceso al parking. Año 2018.

Fuente: Archivo Departamento de Urbanismo del Ayuntamiento de Gandia.
Pese a los problemas y obstáculos encontrados el modelo Simancas como referente y punta de lanza, desde el Ayuntamiento de Gandía se apuesta de forma clara y decidida por la revitalización de los tejidos urbanos.

Las propuestas rehabilitadoras de actuaciones concretas marcadas por la degradación y el mal uso de la vivienda se deben encajar en un puzle de tiempos que coordinen plazos de entrega, realojos y cuotas de edificación entremezclados con licencias de obra, permisos, ayudas y subvenciones. La sincronía es imposible por lo que es fundamental contar con la paciencia y la comprensión de sus vecinos.

Sin lugar a dudas, las operaciones de demoliciones selectivas de edificios que han finalizado su vida útil o presentan síntomas de agotamiento estructural resueltas con inteligencia y sensibilidad devienen en excelentes espacios de oportunidad para la ciudad.

\section{Bibliografía}

BLAT, J. (2000): Vivienda obrera y crecimiento urbano. Editorial Generalitat Valenciana. pág. 145-146

Checa Olmos, J. C. \& Arjona Garrido, A. (2008): "Parias urbanos: segregación residencial de africanos y gitanos en Almería". Revista Ciudad y Territorio Estudios Territoriales, núm. 155 primavera 2008, pág. 109.

Del Águila Garcia. A., (1973) Hogar y arquitectura: revista bimestral de la obra sindical del hogar, $\mathrm{N}^{\circ}$ 5, 1973, pág. 57

DoLs, J. A. (1974): "La OSH y el usuario los barrios de la OSH crónica de un conflicto». Cuadernos de arquitectura y urbanismo, 1974, n. ${ }^{\circ} 105$, pp. 74-81

FoRTUNY. J. (1974): La OSH y la ciudad : introducción a la política del suelo de la OSH. Cuadernos de arquitectura y urbanismo 1974, n. $^{\circ} 105$, pp. $74-81$

HeRvas Mas. J. (2017): Nuevo régimen jurídico de la regeneración urbana. Editorial Thomson Aranzadi. pág. 29-35.

Jubert, J. (1974): "La O.S.H. Características de la gestión de la Obra Sindical del Hogar" Cuadernos de arquitectura y urbanismo, 1974, 105

LASO DE LA VEGA, M., (2020): "Algunas notas sobre la participación de la obra sindical del hogar de Madrid en la política de Vivienda durante el periodo 1939.1959. Actas del congreso Interncional. Pamplona 16 y 17 de marzo de 2020.

LLORENS DURAN, J.I. (1974): "La Obra Sindical del Hogar" Cuadernos de arquitectura y urbanismo. N. ${ }^{\circ} 105$. p. 12

Mut Oltra, F. (1981): Un siglo de Historia Urbana. De la ciudad-baluarte a la ciudad-hormigón. Gandía 1881-1980. Editorial Borja. Pág. 69.

Peñin IBÁÑEz, A. (1978): Ciudad, arquitectura y arquitectos. Escuela Técnica Superior de Arquitectura, p. 122.

UREÑA G. (1979): Arquitectura y Urbanística Civil y Militar en el periodo de Autarquía. (1936-1945). Editorial Istmo. Madrid, p. 11. 